\title{
New RP-UFLC Method for Estimation of Xanthinol Nicotinate in Pharmaceutical Dosage Form
}

\author{
SAGAR SUMAN PANDA*, B.V.V. RAVI KUMAR, \\ PINKAL KUMAR PATEL and JNYANARANJAN PANDA
}

Department of Pharmaceutical Analysis and Quality Assurance, Roland Institute of Pharmaceutical Sciences, Berhampur, Odisha, India sagarguddu2002@gmail.com

Received 12 September 2012 / Accepted 20 October 2012

\begin{abstract}
A novel, accurate and precise RP-UFLC method for determination of xanthinol nicotinate has been developed and validated. Separation was achieved on an Enable $\mathrm{C}_{18} \mathrm{G}$ column (250 mm $\times 4.6 \mathrm{~mm}$ i.d., $5 \mu \mathrm{m})$ using acetonitrile: $10 \mathrm{mM}$ TBAHS (40:60, v/v) as mobile phase at a flow rate of $0.8 \mathrm{~mL} / \mathrm{min}$ and PDA detection at $274 \mathrm{~nm}$. Linearity was observed in the concentration range of $1.0-60 \mu \mathrm{g} / \mathrm{mL}\left(\mathrm{r}^{2}=0.999\right)$. The method was validated for accuracy, precision, stability, specificity, robustness and system suitability. Forced degradation was performed by using $\mathrm{HCl}, \mathrm{NaOH}$, $\mathrm{H}_{2} \mathrm{O}_{2}$, thermal and UV radiation. The method was used successfully for the determination of xanthinol nicotinate in tablet dosage form.
\end{abstract}

Keywords: Xanthinol, RP-UFLC, Validation, Stability, Nicotinic acid

\section{Introduction}

Xanthinol nicotinate (XAN), is a vasodilator having pharmacological action similar to nicotinic acid, used in peripheral and cerebral vascular disorders and hyperlipidemias ${ }^{1}$. Chemically, it is 7-\{2-hydroxy-3-[(2-hydroxyethyl) methylamino] propyl $\}$ theophylline nicotinate (Figure 1).<smiles>CN(CCO)CC(O)Cn1cnc2c1c(=O)n(C)c(=O)n2C</smiles><smiles>O=C(O)c1cccnc1</smiles>

Figure 1. Chemical structure of xanthinol nicotinate

As per literature, there are only a few analytical methods have been reported for determination of xanthinol nicotinate. It includes UV spectrophotometry ${ }^{2}$, HPLC $^{3}$, capillary isotachophoresis ${ }^{4}, \mathrm{GC}^{5}$ and LC-MS ${ }^{6}$ methods. But no RP-UFLC methods were reported so far for determination of xanthinol nicotinate in pharmaceutical dosage form. So a successful attempt was made to develop and validate a fast, simple, precise and accurate RP-UFLC method for determination of xanthinol nicotinate in sustained release tablet dosage form. 
Stability parameters for the drug were assessed by subjecting the drug to forced degradation conditions like acid-alkali hydrolysis, oxidation, thermal and UV radiation. The developed method was also validated as per ICH guidelines for specificity, precision, accuracy, linearity, stability and robustness ${ }^{7}$.

\section{Experimental}

Analytical Grade xanthinol nicotinate was procured from Zydus Healthcare, India. The purity of xanthinol nicotinate was evaluated by obtaining the melting point and infrared spectrum. HPLC grade acetonitrile was procured from Merck Ltd., Mumbai, India. Analytical grade sodium hydroxide, hydrochloric acid and hydrogen peroxide of were procured from S.D. Fine Chem. Ltd., Mumbai, India. The water for HPLC was obtained by using TKA Water Purification System, Germany. Tetra butyl ammonium hydrogen sulfate (TBAHS) purchased from Hi-Media Laboratories Pvt. Ltd., Mumbai, India was of AR grade. The sustained release tablet formulation containing $500 \mathrm{mg}$ of xanthinol nicotinate was purchased from the local market.

\section{UFLC Instrumentation and chromatographic conditions}

Quantitative UFLC was performed on a binary gradient UFLC with two Shimadzu Prominence UFLC LC-20AD pumps, with a $20 \mu \mathrm{L}$ sample injection loop (manual) and SPD M20A PDA detector. The output signal was monitored and integrated using Shimadzu LC Solution Software. An Enable C18G column (250 mm $\times 4.6 \mathrm{~mm}$ i.d., $5 \mu \mathrm{m})$ was used for separation. Chromatographic analysis was carried out at ambient temperature on the column using the acetonitrile: $10 \mathrm{mM}$ TBAHS $(40: 60, \mathrm{v} / \mathrm{v})$ as mobile phase at a flow rate of $0.8 \mathrm{~mL} / \mathrm{min}$ in isocratic mode. The $10 \mathrm{mM}$ TBAHS solution was prepared by accurately weighing $3.3954 \mathrm{~g}$ of TBAHS salt and dissolving it in $1000 \mathrm{~mL}$ of HPLC grade water. Afterwards both the acetonitrile and TBAHS were ultrasonicated (Enertech, India) up to 20 minutes for degassing prior to use. The PDA detection was set at $274 \mathrm{~nm}$. Water bath (Thermolab, India) and UV Chamber (Jain Scientific Glass Works, Ambala, India) were used for forced degradation study of the drug. Analytical balance, Model-GR-202 (AND Instrument India Pvt. Ltd., Gurgaon, India) of sensitivity $0.1 \mathrm{mg}$ was used to weigh the chemicals and reagents.

\section{Preparation of standard and sample solution}

Standard stock solution of the drug was prepared by dissolving $25 \mathrm{mg}$ of the drug in $10 \mathrm{~mL}$ of mobile phase and was ultrasonicated for 5 minutes. Finally, the volume was made up to the $25 \mathrm{~mL}$ with mobile phase, which gave $1000 \mu \mathrm{g} / \mathrm{mL}$ solution.

Twenty tablets containing XAN were weighed and powdered finely. A quantity of tablet powder equivalent to $25 \mathrm{mg}$ of XAN was accurately weighed and transferred into a $25 \mathrm{~mL}$ volumetric flask, containing $10 \mathrm{~mL}$ of mobile phase and ultrasonicated for 20 minutes; the volume was made up to the $25 \mathrm{~mL}$ mark and mixed well. The solution was filtered through a $0.2 \mu \mathrm{m}$ filter to remove particulate matter, if any. The filtered solution was diluted with the mobile phase for analysis as already described. The amount of drug present in the sample solution was calculated by using the calibration curve.

\section{Method validation}

Specificity

The specificity of the method was determined by checking the interference of any of the possible degradation products generated during the forced degradation of XAN. Forced 
degradation was carried out by using $0.1 \mathrm{M} \mathrm{HCl}, 0.1 \mathrm{M} \mathrm{NaOH}, 3 \% \mathrm{v} / \mathrm{v} \mathrm{H}_{2} \mathrm{O}_{2}$, thermal $\left(80{ }^{\circ} \mathrm{C}\right)$ and photolysis $(365 \mathrm{~nm})$ for determining stability nature of the drug. The degradation samples were prepared by taking suitable aliquots of the drug solution and then subjecting each of these aliquots to different stress conditions. After the fixed time period the treated drug solutions were diluted with mobile phase. For every stress condition solution of concentration $10 \mu \mathrm{g} / \mathrm{mL}$ of XAN was prepared.

Acidic degradation was carried out by adding $1 \mathrm{~mL}$ of $0.1 \mathrm{M} \mathrm{HCl}$ and after $45 \mathrm{~min}$ neutralizing the mixture by adding $0.1 \mathrm{M} \mathrm{NaOH}$. Alkaline degradation was carried out by adding $1 \mathrm{~mL}$ of $0.1 \mathrm{M} \mathrm{NaOH}$ and after 45 min neutralizing the mixture by adding $0.1 \mathrm{M}$ $\mathrm{HCl}$. Oxidative degradation was performed by exposing the drug solution to $1 \mathrm{~mL}$ of 3\% (v/v) $\mathrm{H}_{2} \mathrm{O}_{2}$ for $45 \mathrm{~min}$. Thermal degradation was performed by heating the drug solution at $80{ }^{\circ} \mathrm{C}$ on a thermostatically controlled water bath for $45 \mathrm{~min}$. Photolytic degradation was achieved by exposing the drug solution to UV radiation (365 nm) inside an UV chamber for $3 \mathrm{~h}$.

\section{Linearity}

Calibration curve was plotted by taking the peak area on y-axis and concentration $(\mu \mathrm{g} / \mathrm{mL})$ on $\mathrm{x}$-axis in a concentration range from 1.0 to $60 \mu \mathrm{g} / \mathrm{mL}$.

\section{Precision}

Six injections of a fixed amount of XAN were injected in to the UFLC for determining the system precision. The repeatability (intra-day precision) and intermediate precision (interday precision) of the method was also determined. The percent RSD values were calculated for the precision studies.

\section{Accuracy}

To check the accuracy of the proposed method, recovery studies were carried out at 80,100 and $120 \%$ of the test concentration. The recovery study was performed three times at each level and amount of XAN present in the sample was determined.

\section{Robustness}

The system suitability parameters like retention time, theoretical plates, tailing factor and resolution were determined to assess the robustness. Method parameters like flow rate, detection wavelength, organic phase composition and strength of TBAHS solution were deliberately modified for robustness study.

\section{$L O D$ and $L O Q$}

The LOD (limit of detection) and LOQ (limit of quantitation) were determined based on the Signal to Noise ratio. For limit of detection, the $\mathrm{S} / \mathrm{N}$ ratio was taken as 3:1. For limit of quantitation, the $\mathrm{S} / \mathrm{N}$ ratio was taken as 10:1.

\section{Results and Discussion}

Optimization of mobile phase was carried out basing on tailing factor and theoretical plates obtained for XAN. During the trial runs different mobile phase compositions like methanol: water, methanol: $10 \mathrm{mM}$ TBAHS, acetonitrile: water, acetonitrile:10 mM TBAHS, at various compositions (40:60,50:50,60:40,70:30; $/ \mathrm{v})$ and flow rates $(0.8,1.0$ and $1.2 \mathrm{~mL} / \mathrm{min})$ were tested for selection. The mobile phase consisting of acetonitrile: $10 \mathrm{mM}$ TBAHS (40:60, v/v) at a flow rate of $0.8 \mathrm{~mL} / \mathrm{min}$ was selected which gave sharp, symmetric peak. Xanthinol nicotinate separates completely in to xanthinol and nicotinic acid showing two retention times 
$2.631 \mathrm{~min}$ and $3.180 \mathrm{~min}$, respectively with a resolution of 3.488. Retention time for nicotinic acid was confirmed by a separate injection of nicotinic acid solution. The run time was set at 6 minutes for time efficient analysis of the drug in sample matrix. The theoretical plate count was found to be 4399 and 6587 for xanthinol and nicotinic acid, respectively. For further studies the peak profiles for xanthinol was considered. PDA detection was set at $274 \mathrm{~nm}$. The separation was carried out at room temperature. Figure 2 (a) and (b) represents the chromatograms of XAN in marketed formulation and nicotinic acid, respectively.

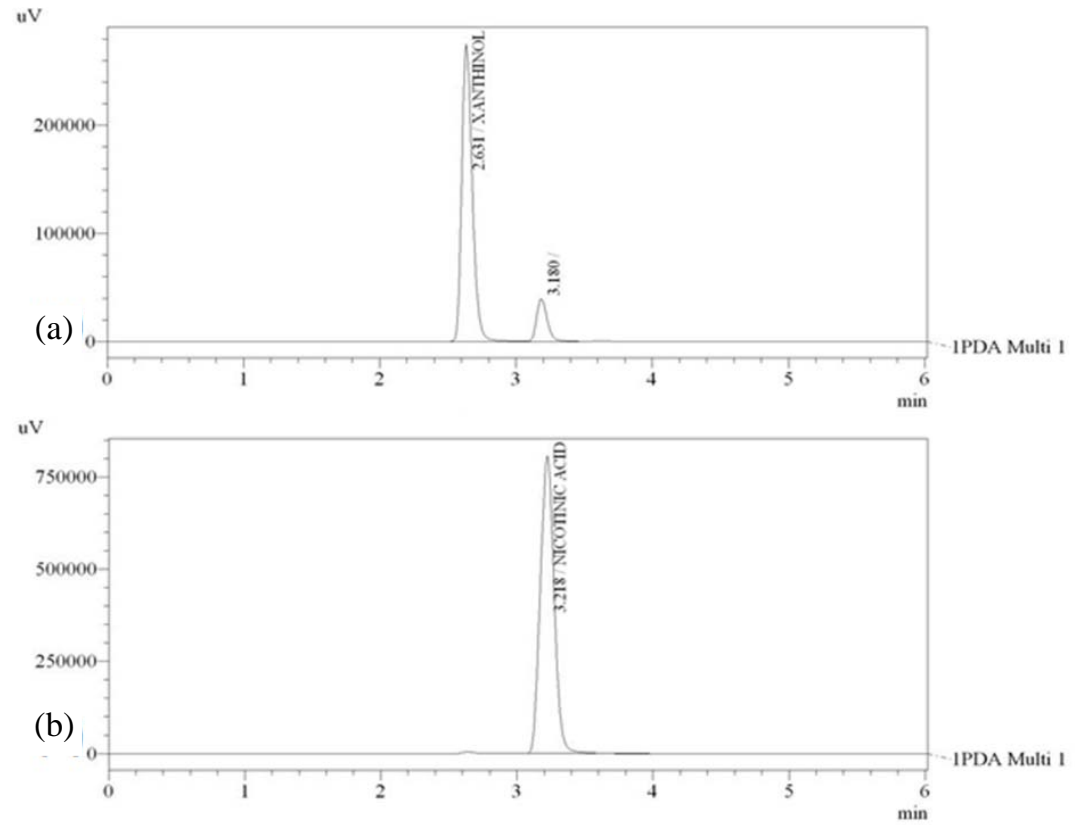

Figure 2. Typical chromatogram of (a) Xanthinol nicotinate in marketed formulation and (b) Nicotinic acid

Specificity of the method was determined by checking any interference due to excipients or possible degradation products. XAN shows minor degradation in acidic, alkaline and thermal stress conditions and shows major degradation in the applied oxidation and photolysis stress conditions. Figure 3(a-e) represents the chromatograms of acid, alkali, oxidation, thermally and photolysis degraded drug. The run time for each stressed drug solution was increased from 6minutes to 10 minutes in order to find out presence of any extra peak due to the possible degradation. The results for forced degradation study are summarized in Table 1.

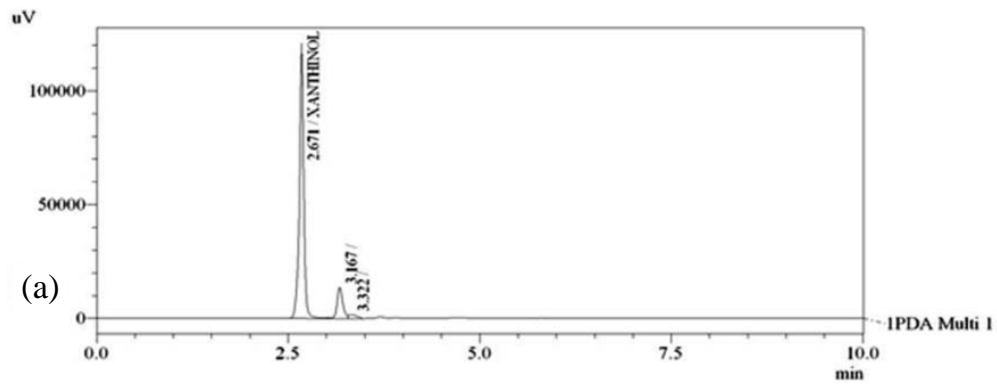



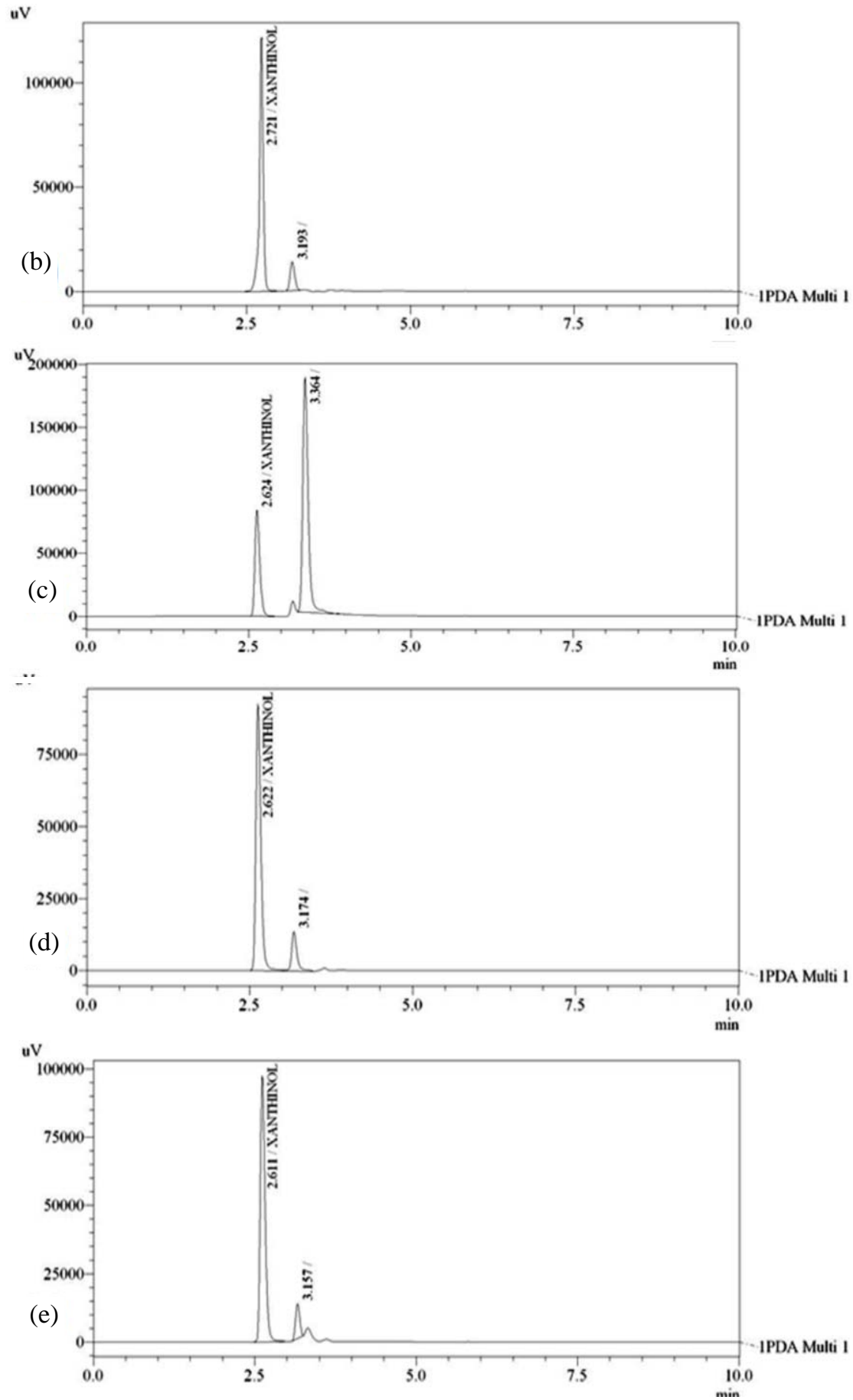

Figure 3. Typical chromatograms of xanthinol nicotinate after treatment with (a) acid, (b) alkali, (c) hydrogen peroxide, (d) thermal and (e) photolysis 
Table 1. Results of forced degradation study

\begin{tabular}{ccc}
\hline Stress Applied & $\begin{array}{c}\text { Retention } \\
\text { Time, min }\end{array}$ & Degradation, \% \\
\hline $0.1 \mathrm{M} \mathrm{HCl}$ & 2.671 & 7.82 \\
$0.1 \mathrm{M} \mathrm{NaOH}$ & 2.721 & 5.61 \\
$3 \% \mathrm{H}_{2} \mathrm{O}_{2}$ & 2.624 & 13.79 \\
$80^{\circ} \mathrm{C}$ & 2.622 & 3.34 \\
UV radiation $(365 \mathrm{~nm})$ & 2.611 & 10.41 \\
\hline
\end{tabular}

The calibration curve was found to be linear over a concentration range of $1.0-60 \mu \mathrm{g} / \mathrm{mL}$ for XAN with correlation coefficient 0.999 . The method was found to be precise as the $\%$ RSD values for precision studies were well below $2 \%$, confirming preciseness of the method. The results of precision studies are shown in Table 2. The average recovery for accuracy study was in the range of $101.79-102.16 \%$ with RSD in the range of $0.41-0.66$. The values show high levels of accuracy of the method. The method was found to be robust in accordance with deliberate changes in mobile phase flow rate $( \pm 0.2 \mathrm{~mL} / \mathrm{min})$, detection wavelength $( \pm 5 \mathrm{~nm})$, organic phase composition $( \pm 2 \%)$ and strength of TBAHS solution $( \pm 0.5 \mathrm{mM})$. The obtained results for robustness study are shown in Table 3.

Table 2. Results of precision study

\begin{tabular}{ccc}
\hline Precision type & Concentration Taken, $\mu \mathrm{g} / \mathrm{mL}$ & Peak Area $^{\mathrm{a}} \pm \mathrm{SD}, \% \mathrm{RSD}$ \\
\hline System Precision & 10 & $664919.5 \pm 4385.25,0.66$ \\
Repeatability & 10 & $654652.3 \pm 2780.44,0.42$ \\
Intermediate precision & 10 & $687298.3 \pm 1554.05,0.23$ \\
\hline
\end{tabular}

${ }^{a}$ Average of six determinations

Table 3. Robustness study

\begin{tabular}{ccccc}
\hline Parameter & $\begin{array}{c}\text { Retention time } \\
\text { min }\end{array}$ & $\begin{array}{c}\text { Theoretical } \\
\text { Plates }(\mathrm{N})\end{array}$ & $\begin{array}{c}\text { Tailing Factor } \\
(\mathrm{T})\end{array}$ & $\begin{array}{c}\text { Resolution } \\
(\mathrm{Rs})\end{array}$ \\
\hline $\begin{array}{c}\text { Flow rate, } \mathrm{mL} / \mathrm{min} \\
0.6\end{array}$ & 3.506 & 4387 & 1.421 & 3.334 \\
0.8 & 2.698 & 4273 & 1.43 & 3.449 \\
1.0 & 2.158 & 4581 & 1.478 & 3.318 \\
Wavelength, nm & & & & \\
269 & 2.698 & 4253 & 1.44 & 3.253 \\
274 & 2.698 & 4273 & 1.43 & 3.449 \\
279 & 2.699 & 4266 & 1.432 & 3.502 \\
Acetonitrile, \% & & & & \\
38 & 2.682 & 4104 & 1.454 & 3.437 \\
40 & 2.698 & 4273 & 1.43 & 3.449 \\
42 & 2.627 & 4960 & 1.449 & 3.337 \\
TBAHS, mM & & & & \\
9.5 & 2.63 & 4553 & 1.452 & 3.332 \\
10 & 2.698 & 4273 & 1.43 & 3.449 \\
10.5 & 2.634 & 4710 & 1.448 & 3.232 \\
\hline
\end{tabular}

The developed method was applied for determination of XAN in tablet dosage form. The result of assay $(n=3)$ for the drug yielded $102.29 \%$ (SD $= \pm 0.4582$ ) of XAN from the sustained release tablet dosage form. The higher percentage of recovery and non interference 
of the formulation excipients in retention time of the drug shows the selectivity of the method for estimation of drug in tablet dosage form. The limit of detection (LOD) and limit of quantitation (LOQ) values were found to be $0.26 \mu \mathrm{g} / \mathrm{mL}$ and $0.85 \mu \mathrm{g} / \mathrm{mL}$, respectively.

\section{Conclusion}

A validated RP-UFLC method has been developed for determination of XAN in extended release tablet dosage form. The results obtained by the stress degradation conditions of the drugs shows that the method is specific and stability indicating. The method was found to be fast, simple, accurate, precise and sensitive. The method was successfully applied for the determination of XAN in tablet dosage form. Further the developed RP-UFLC method may be applied for routine analysis of xanthinol nicotinate in API, pharmaceutical formulations, dissolution medium and biological fluids.

\section{Acknowledgement}

The authors are thankful to Zydus Healthcare for providing the standard drug of Xanthinol nicotinate and M/S Roland Institute of Pharmaceutical Sciences, Berhampur-10, Odisha, India for providing the research facilities.

\section{References}

1. Sweetmann S C, Editor, Martindale-The Complete Drug Reference. $36^{\text {th }}$ Ed., London (UK), Pharmaceutical Press; 2009.

2. $\quad$ Panda S S and Rao M E B, Int J Curr Pharma Res., 2010, 2(1), 43-45.

3. Panda S S, Acharjya S K and Annapurna M M, Eurasian J Anal Chem., 2009, 4, 168-174.

4. Pospisilova M, Jokl V and Dolejsova J, Ceska Slov Farm., 2000, 49(2), 88-90.

5. $\quad$ Roseboom H and Wiese G, Anal Chim Acta, 1979, 108, S401-S403.

6. Liu H Q, Su M X, Di B, Hang T J, Hu Y, Tian X Q, Zhang Y D and Shen J P, J Chromatogr B Analyt Technol Biomed Life Sci., 2008, 873(1), 20-26.

7. International Conference on Harmonization of technical requirements for the Registration of Pharmaceuticals for Human Use: Validation of Analytical Procedures, Text and Methodolgy- Q2 (R1), 2005. 